\title{
DESCRIÇÃO DE UMA ESPÉCIE NOVA DE THYSANOPSIS (DIPTERA, TACHINIDAE) ${ }^{1}$
}

\author{
Ronaldo Toma ${ }^{2}$
}

\begin{abstract}
DESCRIPTION OF A NEW SPECIES OF THYSANOPSIS (DIPTERA, TACHINIDAE). Thysanopsis guimai sp. nov. from Brazil (Mato Grosso) is the second species described for this genus. Redescription of Thysanopsis albicauda Townsend, 1917, and new definition for the genus are done.
\end{abstract}

KEYWORDS. Harrisiini, Sturmiini, Tachinidae, Taxonomy, Thysanopsis.

\section{INTRODUÇÃO}

TownSEND (1917) propôs o gênero monotípico Thysanopsis para T. albicauda. Devido à importância da terminália masculina no reconhecimento das espécies de Tachinidae e, em particular, dos cercos na definição de Thysanopsis, a redescrição de T. albicauda e a redefinição do gênero são apresentadas junto com a descrição da espécie nova.

Lista dos acrônimos. AMNH, American Museum of Natural History, New York; BMNH, The Natural History Museum, London; DZUP, Coleção de Entomologia Pe. Jesus Santiago Moure, Universidade Federal do Paraná, Curitiba; MZSP, Museu de Zoologia, Universidade de São Paulo, São Paulo; USNM, The Natural History Museum, Washington.

\section{Thysanopsis Townsend}

Thysanopsis Townsend, 1917:231, espécie-tipo: T. albicauda TownsEnd, 1917 (designação original); TownsEnd, 1936:189 (chave); 1941:84 (redefinição); GuIMARÃES, 1971:104,187 (cat.).

Diagnose. Fronte estreita, pouco mais larga em direção à pró-fronte, esta subarredondada. Parafaciália ligeiramente mais larga que a parafrontália, levemente mais estreita embaixo. Cerdas ocelares curtas. Tórax com pruinosidade de coloração variada. Escutelo com um par de cerdas basais, dois pares de cerdas laterais e um par de cerdas apicais curtas e cruzadas; um par de cerdas discais. Abdome mais longo que largo com a base pouco mais larga que o tórax, mais estreito em direção ao ápice; machos com sintergito $1+2$ e tergito 3 sem discais e sem marginais; tergito 4 com uma fileira de cerdas marginais (fig. 8). Cercos, vista posterior, com um processo medianoposterior conspícuo (figs. 4, 6). Edeago estreitando-se levemente do epifalo ao acrofalo.

Comentário. Apesar de ter sido arrolado por Townsend (1936) em Harrisiini, Thysanopsis apresenta a morfologia externa mais parecida à dos gêneros de Sturmiini.

\section{Thysanopsis albicauda Townsend}

(Figs. 2-4, 7, 8)

Thysanopsis albicauda TownsEND, 1917:231, holótipo ơ(AMNH), localidade-tipo: Brasil, Mato Grosso, Chapada; GUIMARÃEs, 1971:104,187 (cat.).

1. Parte da Tese de doutorado desenvolvida no Depto de Zoologia da Universidade Federal do Paraná (auxílio CNPq).

2. Museu de Zoologia, Universidade de São Paulo, Caixa Postal 42594, CEP 04299-970, São Paulo, SP, Brasil (bolsista FAPESP). 
Diagnose. Antena preta ou castanho-alaranjada; flagelômero cerca de uma vez e meia o comprimento do pedicelo; pruinosidade abdominal e torácica bastante variável; cercos vista lateral, sub-retos, porção anterior com um processo mediano bastante notável e o terço apical com um tufo de cerdas; surstilos cerca de 0,85 do comprimento dos cercos (figs. 3, 4).

Macho. Comprimento, 9,5-14,5 $\mathrm{mm}$. Cabeça preta ou acastanhada, com pruinosidade cinza; fronte castanha; face cinza-dourada; vértice 0,23 da largura da cabeça; parafrontália cerca da mesma largura ou menos da fronte; pró-fronte cerca de uma vez e meia ou menos da largura da fronte; parafaciália cerca de uma vez e meia ou menos da largura do flagelômero logo abaixo das frontais e cerca de uma vez e meia ou mais na altura subapical deste artículo; antena preta ou castanho-alaranjada; flagelômero cerca de uma vez e meia o comprimento do pedicelo (fig. 2); palpo castanho ou castanhoalaranjado, ápice com pruinosidade testácea; cerdas ocelares curtas; cerdas frontais 1113, estendendo-se até o terço superior da parafaciália, antes do final do pedicelo, pares superiores curtos e finos; verticais externas curtas, cerca de 0,25 do comprimento das verticais internas; parafrontália com pêlos externa e internamente às cerdas frontais, os adjacentes mais espessos; faciália com cerdas de 0,10 a 0,40 do comprimento da vibrissa, estendendo-se pouco além de 0,50 da distância da vibrissa à base da antena, margeadas por várias cerdas menores; gena um pouco menos que 0,30 da altura do olho. Tórax preto; pruinosidade cinza na pleura e escuto; escutelo cinza ou marrom-ferrugíneo. Perna preta. Asa: calíptera com pruinosidade variável. Abdome preto ou castanho; pruinosidade variando bastante: de cinza a marrom-ferrugínea, mais intensa ou não na metade basal dos tergitos. Cercos e surstilos (figs. 3, 4). Vista lateral, cercos sub-retos, porção anterior com um processo mediano bastante notável e o terço apical com um tufo de cerdas. Surstilos cerca de 0,85 do comprimento dos cercos.

Fêmea. Difere do macho pelos seguintes aspectos: cabeça com vértice 0,29 da largura da cabeça lateral; parafrontália entre a mesma largura e uma vez e meia da fronte; pró-fronte cerca de uma vez e meia da largura da fronte; parafaciália entre uma vez e meia e pouco menos do dobro da largura do flagelômero logo abaixo das frontais e mesma largura ou pouco mais antes do término do artículo; pró-fronte levemente projetada em vista lateral; cerdas frontais oito, cruzadas na fronte, estendendo-se até o final do pedicelo, pares superiores reclinados; verticais externas médias, cerca de 0,50 das internas. Abdome: sintergito $1+2$ e tergito 3 com um par de cerdas marginais medianas e sem discais; tergito 4 com uma fileira de marginais médias, longas e espessas.

Distribuição geográfica. Do México (San Luis de Potosí) a Argentina (Misiones).

Comentário. Esta espécie apresenta uma grande variação da pruinosidade no escutelo e abdome; difere de T. guimai sp. nov. pelo flagelômero cerca de uma vez e meia o comprimento do pedicelo (fig. 2), pelo processo mediano-anterior dos cercos e tufo de cerdas do terço apical mais conspícuos e pelos cercos e surstilos relativamente mais curtos.

Material-tipo examinado. Parátipos: BRASIL, Mato Grosso: Chapada, o', XI, H. S. Hebert col. (USNM; ex-coleção S.W. Williston); $80^{7}$,, , idem, (AMNH; etiqueta traz como identificador Arnaud, P.H., 1961, ver ARNAUD, 1963).

Material examinado. MÉXICO, San Luis de Potosí: Tamanzunchale, ơ, 19.IV.1963, W. J. Gertsch. col. (AMNH); Yucatán: Chichen Itza, O', 29.VI., (AMNH). GUATEMALA, Rabinal 3000 pés., ९, 3.VII.1947, F. Johnson \& Vaurie col. (AMNH). HONDURAS. Tegucigalpa, O', 15.IX.1917, F. J. Dyer col. (AMNH). COLOMBIA, Susumuco,, , II.1934, M. Apolinar col. (MZSP). PERU. San Martin: (1600 pés), ơ', 5.XII.1946, 
J. C. Pallistter \& F. Johnson col. (AMNH); Huanuco: Tingo Maria (entrada do Rio Baures), 2 o', IX-X.1964, J. Bouseman \& J. Lussenhop col. (AMNH); Madre Dios: Callunga, + , (BMNH; ex-coleção C. J. Wainwright). BOLÍVIA, Beni: Rio Itenez (4 km acima Costa Marques, Brasil),, , 12-18.IX.1964, J. Bouseman \& J. Lussenhop col. (AMNH); Rio Mamore, (aprox. 5 km NO da entrada do Rio Grande), + , 4.VIII.1965, J. Bouseman col. (AMNH). BRASIL, Amazonas: Manaus (26 km NE Reserva Ducke), 5 o $^{\top}, 20 . X .-24 . X I .1988$, J. A. Rafael col. (MZSP); Rondônia: Vilhena, + , 22.VII-5.VIII.1983, F. J. A. Peralta col. (MZSP); Mato Grosso: Chapada, 47 O $^{7}, 36$ P, H. S. Hebert col. (AMNH; ex-coleção Williston); Salobra, O’, 13-29.V.1942 (MZSP); Três Lagoas, Fazenda Floresta, $20^{7}$, 13-20.IX.1964, Exp. Dep. Zool. col. (MZSP); Goiás: Campinas, ơ I. I934, Spitz col. (MZSP); 1 o', 21.XII.1936, Borgmeyer \& H. S. Lopes col. (MZSP); Anápolis, O, 15.II.1937, Serviço Febre Amarela, M.E.S. col. (MZSP); Minas Gerais: Arceburgo, O’, + , III.1945, M.P. Barreto col. (MZSP); São Paulo: Araçatuba, Córrego Azul, 4 ठð, II.1946, E. X. Rabello col. (MZSP); Avanhandava, O’, II.1946, M. P. Barreto col. (MZSP); Barueri, ơ, , , 28.XI.1954-8.IV.1957, K. Lenko col. (MZSP); Cajuru, Oásis dos Coqueiros, †, II.1945, M. P. Barreto col. (MZSP); Paraná: Londrina, O', IV.1945, M.P.Barreto col. (MZSP); Santa Catarina: Corupá, O’, I.1946 (AMNH); Nova Teutônia, 27 O’, 11 \%, III.1916-X.1970, F. Plaumann col. (MZSP). ARGENTINA, Misiones: Alto Paraná, ơ, 7-21.III.1934 (BMNH; ex-coleção K. J. Hayward).
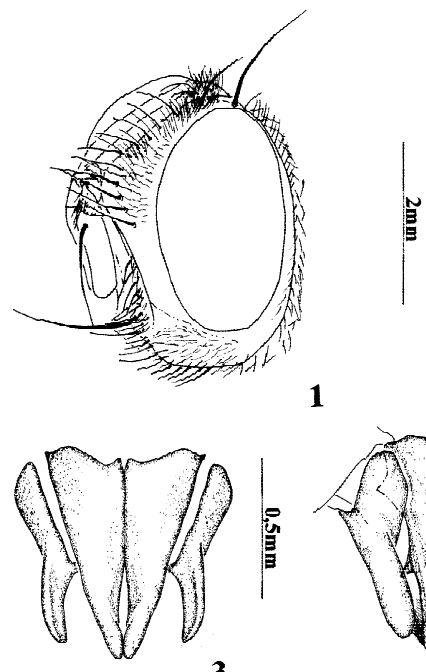

3

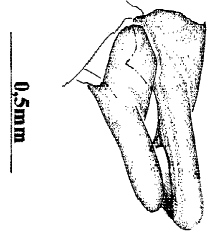

4

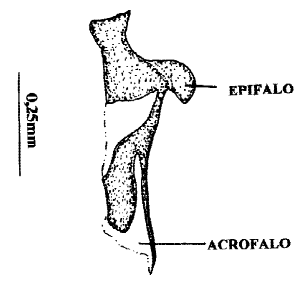

7
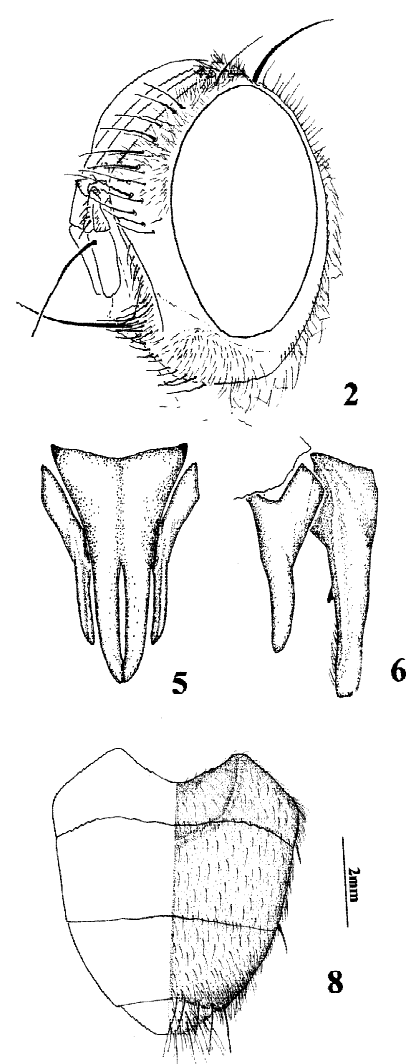

Figs. 1-8. Cabeça, vista látero-frontal: 1, Thysanopsis guimai sp. nov.; 2, T. albicauda Townsend, 1917. Cercos e surstilos, vista posterior e lateral, respectivamente: 3, 4, T. albicauda; 5, 6, T. guimai (mesma escala). Edeago, vista lateral: 7, T. albicauda. Abdome, vista dorsal: 8, T. albicauda. 


\section{Thysanopsis guimai sp. nov.}

(Figs. 1, 5, 6)

Diagnose. Escapo e pedicelo alaranjados, flagelômero preto, este cerca do dobro do pedicelo; cercos e surstilos (figs. 5, 6) mais alongados do que os de T. albicauda.

Macho. Comprimento, 12,5-14,0 mm. Cabeça: pruinosidade cinza sobre fundo pardo, mais escurecido na parafrontália; fronte castanho-escura; vértice 0,24 da largura da cabeça; parafrontália cerca da mesma largura da fronte ou pouco mais estreita; prófronte cerca de uma vez e meia da largura da fronte; parafaciália entre pouco mais de uma vez e meia e o dobro da largura do flagelômero logo abaixo das frontais e pouco menos de uma vez e meia na altura subapical deste artículo; antena com escapo e pedicelo alaranjados, flagelômero preto; este cerca do dobro do pedicelo (fig. 1); palpo alaranjado; cerdas ocelares curtas; verticais externas curtas, cerca de 0,25 do comprimento das verticais internas; cerca de 11 cerdas frontais, maiores e mais espessas em direção à pró-fronte, estendendo-se até o terço superior da parafaciália, logo abaixo do final do pedicelo, pares superiores finos e curtos; pêlos da parafrontália estendendo-se até logo abaixo das cerdas frontais; faciália com cerdas de 0,20 a 0,40 do comprimento da vibrissa, estendendo-se pouco mais da metade da distância da vibrissa à base da antena, margeadas por cerdas menores; gena pouco menos de 0,30 da altura do olho. Tórax preto; pruinosidade cinza; escutelo castanho. Cerdas escutelares seguem o padrão do gênero. Perna preta. Abdome castanho, escurecido longitudinalmente no centro no tergito 5 e na margem de tergito 4; padrão de quetotaxia do gênero. Cercos e surstilos (figs. 5, 6) relativamente mais alongados que os de T. albicauda. Surstilos cerca de 0,75 do comprimento dos cercos.

Comentário. Difere de T. albicauda por apresentar o flagelômero e os cercos mais alongados.

Etimologia. Esta espécie foi descrita em homenagem ao Dr. José Henrique Guimarães (MZSP).

Material-tipo. Holótipo ơ', BRASIL, Mato Grosso: Chapada, XI, H. S. Hebert col. (AMNH; ex-coleção S. W. Williston); Parátipos: $20^{7}$, idem (um exemplar sem menção de data) (AMNH); O', idem (MZSP); $0^{\prime}$, idem (DZUP).

Agradecimentos. Aos curadores Caroline S. Chaboo (AMNH), Nigel Wyatt (BMNH), Claudio José Barros de Carvalho (DZUP) e Francisca C. do Val (MZSP), pelo empréstimo do material.

\section{REFERÊNCIAS BIBLIOGRÁFICAS}

Arnaud, P. H. 1963. Types of the tachinidae (Diptera) in The American Museum of Natural History. Bull. Am. Mus. nat. Hist., New York, 125: 103-137.

Guimarães, J. H. 1971. Family Tachinidae. In: Papavero, N. ed. A catalogue of the Diptera of the Americas South of the United States. São Paulo, Universidade de São Paulo. v. 104, 333p.

Townsend, C.H.T. 1917. Second paper on Brazilian Muscoidea collected by Herbert H. Smith. Bull. Am. Mus. nat. Hist., New York, 37 (6): 221-233.

. 1936. Manual of Myiology Pt. IV, in twelve parts. Oestroid classification and habits (Dexiidae and Exoristidae). Pt IV. Itaquaquecetuba, C. H. T. Townsend, 303p.

. 1941. Manual of Myiology, in twelve parts. Oestroid generic diagnoses and data (Goniini to Trypherini). Pt XI. Itaquaquecetuba, C. H. T. Townsend. 342 p.

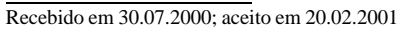

